\title{
Economic feasibility evaluation of shale gas stratified development in Chongqing area
}

\author{
Chengxin Yin ${ }^{1}$, Jun Zhou ${ }^{2, *}$ \\ ${ }^{1}$ Chengdu Aeronautic Polytechnic, Chengdu, 610100, China \\ ${ }^{2}$ Sinopec Research Institute of Petroleum Engineering, Beijing, 100101, China
}

\begin{abstract}
Shale gas as a clean green energy has been rapidly developed in China. At present, the vertical production rate of shale gas in Chongqing area is low, and it is difficult to take into account the whole highquality shale segment with thickness of tens of meters only by one well pattern. In this paper, the internal rate of return (IRR) is used to calculate the impact of different costs and exploitation conditions on the development effect of two shale gas layers. The results show that shale gas development will be profitable only when the cost per well is controlled at around 70 million and production is provided at more than 100 million cubic meters. Domestic producers should further reduce the cost of shale gas development, increase the productivity of single well and maximize the benefit of domestic shale gas development by means of integrated innovation and technological optimization.
\end{abstract}

\section{Introduction}

Shale gas is a new clean natural gas resource, which has gained rapid development in North America, China and other countries and regions. After breakthroughs and large-scale development of shale gas in the United States, shale gas accounts for about 40 percent of the country's annual gas production. In China, due to environmental protection and winter heating, the demand for natural gas is increasing. However, the increment of geological reserves and exploitation degree of conventional natural gas is limited, and the dependence of domestic natural gas is increasing, so it is of great value to improve the development effect of domestic shale gas.

At present, the vertical production rate of shale gas in Chongqing area is low, and it is difficult to take into account the whole high-quality shale segment with thickness of tens of meters only by one well pattern. The shale gas plays in the United States have been developed in three to four vertical well patterns. Therefore, from the perspective of economic benefits, this paper discusses the feasibility of realizing three-dimensional development of shale gas in vertical two sets of well patterns, and provides theoretical basis for the next large-scale commercial development of shale gas in Chongqing.

\section{Domestic shale gas development status}

With the shale gas revolution underway in the United States, China stepped up its efforts to explore and develop shale gas from around 2010. According to the U.S. Energy Information Administration (EIA), China has 31.6 trillion cubic meters of recoverable shale gas, ranking first in the world. According to the latest survey and calculation by the Ministry of Natural Resources, the recoverable reserves of shale gas in China are 21.8 trillion cubic meters, still higher than the geological reserves of the United States.

At present, shale gas fields with relatively large scale development are mainly distributed in Sichuan Basin. Sinopec shale gas development achieved a breakthrough in Fuling, Chongqing in 2012, thus kicking off the prelude of domestic shale gas development. Chongqing Fuling Shale Gas Field is the first national shale gas demonstration zone, with a cumulative gas production of 200 cubic meters in 2018. It is the first shale gas development zone with commercial exploitation value after shale gas development in the United States. At the same time, CNPC has carried out large-scale exploration and development of shale gas in Changning and Weiyuan areas of Sichuan province. At present, the shale gas resources in Weiyuan block are about 620 billion cubic meters, and the recoverable capacity is more than 260 billion cubic meters.

\section{Production prediction model of shale gas well developed by stratified system}

The fracture system and two-phase seepage mechanism formed after fracturing of shale gas Wells are complicated. In order to simulate the production process of shale gas horizontal well after multi-stage fracturing as accurately as possible, the dual media model was used to assign values to shale matrix system and natural fracture system respectively, including porosity and permeability, relative permeability, etc (Figure 1).

*Corresponding author: zhou_sripe2015@126.com 


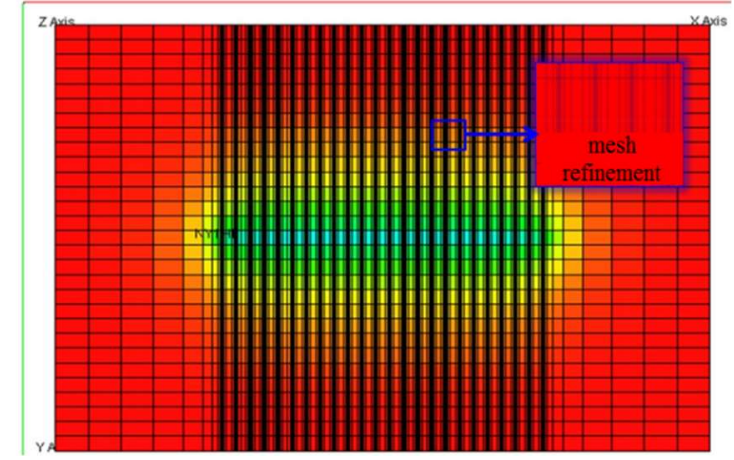

Figure 1. Fracture network fracturing model for shale gas.

The optimized daily production is shown in Figure 2. Taking the 15-year cumulative production as the target, the daily production changes under different reservoir characteristics are calculated according to the distribution of Wells in two development layers. In terms of artificial fracture parameters, the number of fracture stages is 15 20 , the length of semi-supported fracture is $200-250 \mathrm{~m}$, and the conductivity is $3-4$ D.cm.

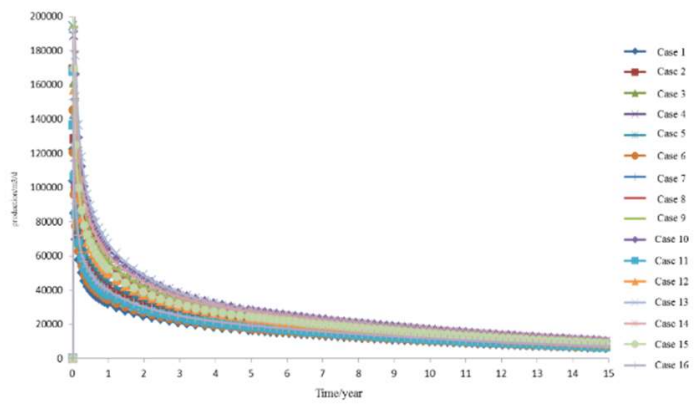

Figure 2. The change of daily output of orthogonal design scheme with time.

Through numerical simulation, it can be concluded that the average initial productivity of the well is $20 \times 10^{4} \mathrm{~m}^{3} / \mathrm{d}$. Considering the rapid decline rate of shale gas production and development, according to the production decline model, it is calculated that the cumulative production of shale gas in the two development layers is about 1.5$2.1 \times 10^{8} \mathrm{~m}^{3}$ in 15 years.

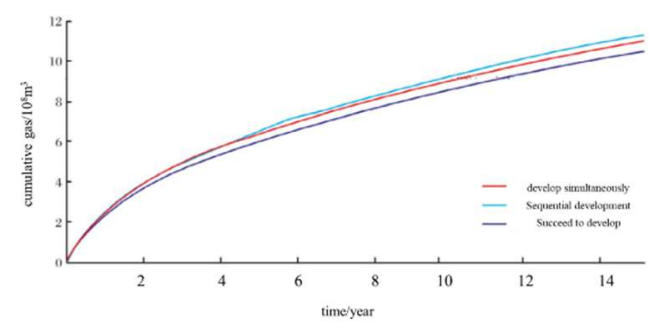

Figure 3. Cumulative gas production under different production modes.

In order to quantify the degree of interference caused by the production of the upper and lower well patterns and explore the effect of sequential production on the mitigation of inter-well interference, three production modes were simulated: single well succession, two Wells successively and two Wells synchronously. A unified production system of $8 \times 104 \mathrm{~m}^{3} / \mathrm{d}$ was adopted for 15 years, and the EUR changes of 15 years were simulated (FIG. 2), with EUR respectively being $1.13 \times 10^{8} \mathrm{~m}^{3}, 1.05 \times 10^{8} \mathrm{~m}^{3}$, $1.11 \times 10^{8} \mathrm{~m}^{3}$. After half a year of production, the area of pressure drop funnel increased by $13.7 \%$ compared with that without offset well production, and the production formation pressure level was basically the same. The results show that inter-well interference is inevitable in the development process of small well spacing. For a gas reservoir with a single closed volume, inter-well interference affects $6.8 \%$ of the production of adjacent Wells. A sequential approach could reduce the impact to less than 2 per cent.

\section{Economic evaluation method of shale gas development benefit in stratified system}

When calculating the economic benefit of shale gas development, we should not only consider the cost of shale gas well construction, the law of production decline, but also consider the time value of investment capital. Therefore, net present value method and internal rate of return method are mainly used for economic evaluation. In this paper, the internal rate of return method (IRR) is used to calculate the economic benefits of shale gas development in China. Currently, the benchmark rate of return used by CNPC and Sinopec in shale gas development is generally $8 \%$, and the calculation formula is as follows:

$$
\sum_{t=0}^{n}(C I-C O)_{t}(1+i)^{-t}=0
$$

including $C I$ is the cash inflow, ten thousand yuan; $C O$ is the amount of cash outflow, ten thousand yuan; $i$ is the discount rate; $\mathrm{n}$ Is the production life; $t$ is the year of production.

Taking a typical shale gas well in Chongqing as an example, the drilling cost is 35 million yuan, fracturing construction cost is 30 million yuan, other costs are about 5 million yuan, the total cost is about 70 million yuan. According to the above calculation, the cumulative output in 15 years is about $1.2 \times 108 \mathrm{~m} 3$. At the same time, due to the different geological characteristics and production technology, the production volume of the area fluctuates, and the production range is $0.6-1.6 \times 108 \mathrm{~m} 3$. Therefore, the cost price of shale gas under different production and development costs (yuan $/ \mathrm{m} 3$ ) is calculated in the case of $8 \%$ benchmark yield. 
Table 1. Shale gas needs a cost gas price to achieve an $8 \%$ benchmark yield.

\begin{tabular}{|c|c|c|c|c|c|c|}
\hline $\begin{array}{l}\text { Investmen } \\
\text { t cost per } \\
\text { well / ten } \\
\text { thousand } \\
\text { yuan }\end{array}$ & $\begin{array}{c}0.6 / \\
\text { hundr } \\
\text { ed } \\
\text { millio } \\
\text { n } \\
\text { cubic }\end{array}$ & $\begin{array}{c}0.8 / \\
\text { hundr } \\
\text { ed } \\
\text { millio } \\
\mathrm{n} \\
\text { cubic }\end{array}$ & $\begin{array}{l}\text { 1/hun } \\
\text { dred } \\
\text { milli } \\
\text { on } \\
\text { cubic }\end{array}$ & $\begin{array}{c}1.2 / \mathrm{hu} \\
\text { ndred } \\
\text { millio } \\
\mathrm{n} \\
\text { cubic }\end{array}$ & $\begin{array}{l}1.4 / \mathrm{hu} \\
\text { ndred } \\
\text { millio } \\
\mathrm{n} \\
\text { cubic }\end{array}$ & $\begin{array}{c}1.6 / \mathrm{h} \\
\text { undr } \\
\text { ed } \\
\text { milli } \\
\text { on } \\
\text { cubic }\end{array}$ \\
\hline 5000 & 2.18 & 1.74 & 1.33 & 1.06 & 0.91 & $\begin{array}{l}0 \\
. \\
7 \\
4 \\
0\end{array}$ \\
\hline 6000 & 2.63 & 2.11 & 1.58 & 1.25 & 1.05 & $\begin{array}{l}\dot{8} \\
8\end{array}$ \\
\hline 7000 & 3.08 & 2.47 & 1.84 & 1.44 & 1.21 & $\begin{array}{l}0 \\
4\end{array}$ \\
\hline 8000 & 3.53 & 2.83 & 2.11 & 1.64 & 1.36 & $\begin{array}{l}5 \\
1 \\
5 \\
1\end{array}$ \\
\hline 9000 & 4.04 & 3.22 & 2.38 & 1.85 & 1.53 & $\begin{array}{l}3 \\
6 \\
1\end{array}$ \\
\hline 10000 & 4.52 & 3.61 & 2.66 & 2.06 & 1.69 & 4 \\
\hline
\end{tabular}

According to the calculated results in Table 1, the cost gas price drops from 3.08 yuan $/ \mathrm{m}^{3}$ to 1.04 yuan $/ \mathrm{m}^{3}$ when the cumulative production of a single well increases from 0.6 million cubic meters to 160 million cubic meters under the cost of conventional investment of 70 million yuan/well. At present, the average single production of shale gas is about 0.8 to 100 million cubic meters, and the current weather price is 2.6 yuan $/ \mathrm{m}^{3}$. If the well construction cost exceeds 80 million yuan/well, then the development benefit of the producer remains at a low level. In this case, a well production of more than 100 million cubic meters would be beneficial to increase revenue and further enhance shale gas development in the area.

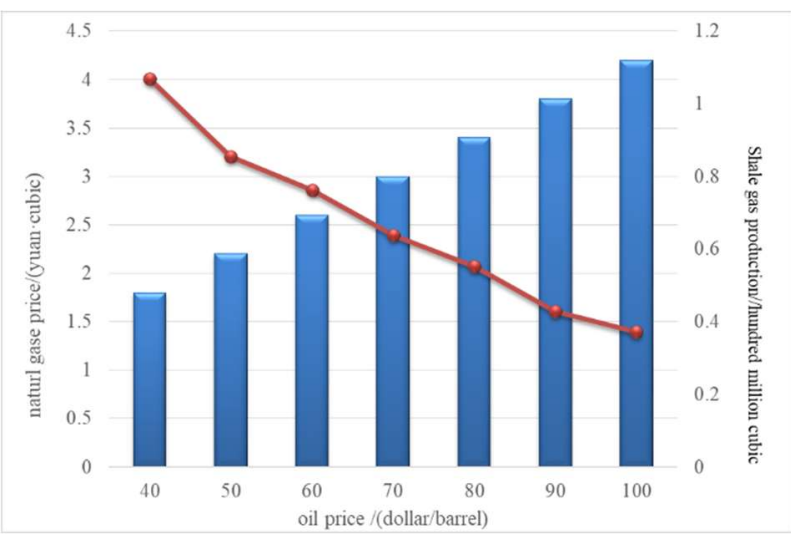

Figure 4. Shale gas production per well at different oil prices.

The required production capacity of a single well is calculated based on the corresponding LNG import gas price under different oil prices, that is to say, the cost price of domestic shale gas to realize profitable development should be lower than the LNG import gas price to achieve productive efficiency. Based on oil price fluctuations in recent years, the cumulative production required for 15 years of shale gas production per well at a production cost of $\$ 40$ - $\$ 100$ per barrel was calculated. As can be seen, when the oil price is $\$ 40 / \mathrm{BBL}$, the cumulative production of shale gas per well needs to reach 1.07 million cubic meters, which is about the most effective shale gas Wells in China. At an oil price of \$50-60 / BBL, the demand for backflow is reduced to $0.762-0.854$ hundred million cubic, which is about the average for most conventional shale gas production wells in the country today. At oil prices of $\$ 80$ / BBL and above, the demand for cumulative production is reduced to $0.372-0.553$ hundred million cubic for deep shale gas production wells to be productive.

\section{Countermeasures for sustainable development of Shale gas in China}

\subsection{Scientific and technological innovation}

The drilling and fracturing technology of shale gas in China mainly learns from the experience of shale gas development in the United States, and has made considerable achievements in the early stage, promoting the production and construction of shale gas in China. However, with the large-scale shale gas exploration and development in China, many technical problems have gradually emerged. The formation conditions of shale reservoirs in the United States are better, and the shale reservoirs in China are more complex, and the physical properties and gas content are relatively poor.

In addition, the country's vast shale gas reserves lie deeper than those in the United States, and existing drilling and production techniques are better applied to reservoirs in the range of 3,000-3,500 meters. For the shale reservoir with a depth of 4000 meters, the gas production effect of most deep shale gas exploration Wells is not as expected, except for some Wells with good geological conditions and high gas production. Therefore, it is necessary to study the formation and enrichment mechanism of shale gas, theory and exploitation technology of deep shale gas in China based on the actual situation in China. On the basis of absorbing and mastering foreign advanced shale gas exploitation technology, the current situation that domestic deep shale gas and atmospheric shale gas are difficult to effectively develop is solved through independent innovation.

\subsection{Cost decreasing and benefit increasing}

Although China's shale gas production in 2018 increased by 20.96 percent from 2017, it still accounted for less than 8 percent of the country's total natural gas production, far below the level of shale gas development in the United States. One of the main reasons is that the cost of developing shale gas in China is still higher than in the United States. Because domestic shale gas fields such as Fuling shale gas field in Chongqing and Weiyuan shale gas field in Sichuan are located in mountainous areas, the 
cost of well site construction, pipeline placement and material transportation has been difficult to reduce.

After several years of development, the construction cost of a single well for shale gas in China has been reduced from about 100 million yuan at the beginning to about 5070 million yuan. However, compared with conventional natural gas Wells, it has no advantage in terms of output or cost, while the cost of a single well for shale gas in the United States is close to that of conventional gas wells. The high cost of well construction makes it difficult for small and medium-sized enterprises to enter the shale gas development market, and they can only engage in technical services, on-site construction and other work. Therefore, it is necessary to realize the localization of key tools and materials by further digesting and absorbing foreign advanced technology. At the same time, improve shale gas exploration and development technology, through process optimization to minimize the domestic shale gas drilling and fracturing construction costs, such as improving drilling speed, the use of low oil-water ratio oil-based drilling fluid technology, reduce unilateral costs, reduce drilling costs. The use of low-cost quartz sand instead of ceramic, appropriate to reduce the construction scale or reduce the number of sections.

\section{Conclusion}

This paper studies the economic benefits of shale gas development in Chongqing region from the angle of technology and economy, and puts forward corresponding countermeasures for the sustainable development of shale gas in China.

(1) The internal rate of return (IRR) is used to calculate the impact of different costs and production conditions on shale gas development. The calculation results show that only when the cost per well is controlled at about 70 million yuan and the production is provided at more than 100 million cubic meters, can the shale gas Wells in China have obvious profit effect. Moreover, consider that direct subsidies for shale gas will be phased out. Domestic producers should further reduce the cost of shale gas development, increase the productivity of single well and maximize the benefit of domestic shale gas development by means of integrated innovation and technological optimization.

(2) The countermeasures to improve the economic benefits of shale gas development in China are put forward from the perspectives of technological innovation, cost reduction and efficiency increase, and multi-type policy support, which are helpful to realize the economic and effective development of shale gas resources in China.

\section{References}

1. Liu jing, Xu Haitang, Yu Guo, et al. Development indices and potential of shale gas, Sichuan basin[J]. Natural Gas Explora-tion and Development, 2014, 37(2): 45-47.

2. Dong Dazhong, Shi Zhensheng, Guan Quanzhong, et al. Progress, challenges and prospects of shale gas exploration in the Wufeng--Longmaxi reservoirs in the Sichuan Basin[J]. Natural Gas Industry, 2018, 38(4): 67-76.

3. Zhou Shouwei, Jiang Wei, Zhang Chunyang, et al. The enlightenment on shale gas exploration and development in China getting from Eagle Ford in American[J]. Engineering Scinences, 2012,14(6):1621.

4. Liang Xing, Wang Gaocheng, Zhang Jiehui, et al. High-efficiency integrated shale gas development model of Zhaotong National Demonstration Zone and its practical enlightenment[J]. China petroleum exploration, 2017,22(1):29-37.

5. ZHANG Jiaming, GUO Xiaoxia, HE Wenyuan. Comparative study on shale gas development in southern Sichuan and the ways to reduce costs \& increase efficiency[J]. International Petroleum Economics Monthly, 2018, 26 (9) : 31-38.

6. Ma Xinhua \& Xie Jun. Advances in shale gas exploration and development in southern Sichuan[J]. Petroleum Exploration and Development, 2018, 45(1): 161-169.

7. Shang Shaofen, Yan Hong, Wu Jian, et al. Production characteristics and development modes of shale-gas wells, Changning gasfield, Sichuan Basin[J]. Natural Gas Exploration and Development, 2018, 41(4): 6975.

8. WANG Xiuzhi, SHI Zhiliang, LONG Shengxiang, et al. Study on economic and reasonable well spacing of Changxing Formation reservoir development in Yuanba Gas Field [J].Fault-Block Oil \& Gas Field, 2012, 19 (3) : 340-342.

9. GAO Shikui, ZHU Wenli, YIN Cheng. An economic analysis of shale gas resources: A case study of the Marcellus shale play[J]. Natural Gas Industry, 2014, 34(6): 141-148.

10. LI Qinghui, CHEN Mian, JIN Yan. Economic influence of hydraulic fracturing parameters on horizontal wells in shale gas bed[J]. Special Oil \& Gas Reservoirs, 2013, 20(1): 146-150.

11. Jiang Xinchun, Sun Qinping, Zhao Qun, etc. Production Characteristics and Economic Benefit Classification Method of Shale Gas Wells in Southern Sichuan[J].SINO-GIOBAL ENERGY,2021,26(8):43-50.

12. Fang Dazhi, Qian Jin, Mei Junwei,etc. Layer series division for development of shale gas of Pingqiao anticline in Nanchuan Block and reasonable well spacing optimization[J].Reservoir evaluation and development, 2021,11(2):78-84.

13. Wen Zhentao, Yuan Dongshan, Chen Lan,etc. Quantitative analysis on the risk parameter interval of ecnomic evaluation of shale gas fields[J].Journal of Yangtez University, 2017,14(15):77-81. 